\title{
Diagnosis and management of iliofemoral deep vein thrombosis: clinical practice guideline
}

\author{
David Liu MD, Erica Peterson MD MSc, James Dooner MD, Mark Baerlocher MD, Leslie Zypchen MD, \\ Joel Gagnon MD, Michael Delorme MD, Chad Kim Sing MD, Jason Wong MD, Randolph Guzman MD, \\ Gavin Greenfield MD, Otto Moodley MD, Paul Yenson MD; for the Interdisciplinary Expert Panel \\ on Iliofemoral Deep Vein Thrombosis (InterEPID)
}

CMAJ Podcasts: author interview at: https://soundcloud.com/cmajpodcasts/141614-guide

Competing interests: See end of article.

This article has been peer reviewed.

Correspondence to:

David Liu, dave.liu@vch.ca

CMAJ 2015. DOI:10.1503 /cmaj.141614
$\mathrm{V}$ enous thromboembolism, presenting as deep vein thrombosis (DVT) or pulmonary embolism, affects over 35000 Canadians each year. ${ }^{1}$ It is associated with substantial morbidity, mortality and burden on the Canadian health care system, with onemonth mortality rates estimated at $6 \%$ for DVT and $12 \%$ for pulmonary embolism. ${ }^{1}$

Iliofemoral DVT is defined as thrombus involving the iliac and/or common femoral veins, with or without extension to the inferior vena cava; it represents about one-quarter of all cases of DVT. ${ }^{2,3}$ The natural history of iliofemoral DVT is associated with a higher risk of adverse outcomes relative to femoropopliteal or distal DVT, with examples of such outcomes including severe leg pain and swelling, limb ischemia and increased risk of recurrent venous thromboembolism and post-thrombotic syndrome., ${ }^{4,5}$

The poor outcomes observed in patients with iliofemoral DVT treated with standard anticoagulant therapy have led to exploration of alternative therapeutic options. Trials of strategies to reduce or remove thrombi, such as systemic thromboly-

\section{- Ker poInts}

- Ultrasonography is the diagnostic imaging modality of choice for patients with suspected deep vein thrombosis (DVT).

- Systemic anticoagulation is indicated for all patients with iliofemoral DVT, although the appropriate type of anticoagulant depends on patient- and treatment-related factors.

- Retrievable inferior vena cava filters should be considered for patients with iliofemoral DVT who have a contraindication to anticoagulation and who have scheduled follow-up.

- For all patients with phlegmasia cerulea dolens, endovascular or surgical clot removal is required, whereas select patients with iliofemoral DVT are candidates for endovascular thrombus removal to prevent sequelae of post-thrombotic syndrome.

- Compression therapy may be considered for the treatment of established post-thrombotic syndrome, but it is unlikely to prevent development of the syndrome.

sis, ${ }^{6,7}$ catheter-directed thrombolysis ${ }^{8}$ and surgical thrombectomy, ${ }^{9-11}$ have resulted in improved long-term vessel patency and reduced postthrombotic syndrome relative to anticoagulation alone. However, these procedures are not uniformly available, are resource intensive and have their own potential complications.

\section{Scope}

This guideline is intended to assist Canadian primary care physicians in the assessment and management of patients with iliofemoral DVT. We include guidance as to which patients may benefit from early triage and transfer to tertiary care institutions for clot removal and reduction, a critical aspect in the management of this condition.

\section{Methods}

This consensus guideline provides recommendations on the diagnosis and management of iliofemoral DVT, including the use of anticoagulation, thrombus removal strategies and inferior vena cava filters, as well as the treatment of postthrombotic syndrome.

We developed the guideline recommendations by rating the importance of outcomes and the confidence of effect estimates and using grading mechanisms in accordance with methods proposed in the Grading of Recommendations Assessment, Development and Evaluation (GRADE) system. ${ }^{12-16} \mathrm{We}$ applied the American Heart Association clinical practice methodology ${ }^{17}$ (Box 1) to classify the recommendations and levels of evidence and translated these to the corresponding GRADE strengths of recommendations and confidence in effect estimates (Box 2). ${ }^{17-20} \mathrm{We}$ applied the Appraisal of Guidelines for Research and Evaluation (AGREE II) appraisal tools for clinical practice guidelines. ${ }^{21,22}$ 


\section{Panel composition}

A multidisciplinary working group of 13 members, assembled under the auspices of the University of British Columbia Departments of Radiology and Internal Medicine, consisted of five hematologists (E.P., L.Z., M.D., O.M., P.Y.), three vascular surgeons (J.D., J.G., R.G.), three radiologists (D.L., M.B., J.W.) and two primary care physicians working in the emergency department and outpatient settings (C.K.S., G.G.).

\section{Management of conflicts of interest}

Panel members disclosed financial and intellectual conflicts of interest. Each potential conflict of interest was evaluated to determine whether it would preclude participation. During this process, no relevant conflicts of interest were identified, and all members fully participated.

\section{Development of recommendations}

Content experts on the panel participated in a series of teleconferences and email correspondence to determine the scope and topics to be addressed by the guideline. At the outset of the guideline development process, the working group identified outcomes deemed important to patients. For each of these topics, we searched the literature via the PubMed, Embase and MEDLINE databases through October 2012, with updating of database searches until publication of the guideline in September 2015. The search was limited to studies conducted in humans and published in English. Topics were divided among the panel members, and within each category, members identified relevant existing guidelines and systematic reviews for each topic. We performed more extensive literature reviews for topics for which no guideline or systematic review existed or for which such materials were published two or more years before the start of the guideline development process. Members proposed consensus statements with associated summaries of the evidence, and consensus was achieved using a modified Delphi consensus panel format. ${ }^{23}$

\section{Recommendations}

The recommendations are summarized in Box 2, and a decision algorithm is provided in Figure 1.

\section{Diagnosis of iliofemoral DVT}

The approach to the diagnosis of suspected iliofemoral DVT is well established. It involves a combination of assessment of clinical pretest probability (e.g., Well scoring system for DVT and pulmonary embolism), D-dimer testing and Doppler ultrasonography ${ }^{24,25}$ and does not differ from the approach used for all patients with suspected DVT. ${ }^{24}$ However, patients with iliofemoral DVT are at risk of limb ischemia, and it is therefore critical that the initial history and physical examination rule out phlegmasia cerulea dolens, a condition associated with high rates of amputation and death. ${ }^{26}$ Symptoms and signs suggestive of phlegmasia cerulea dolens, including severe pain, massive edema, cyanosis, pulse deficit, skin bullae and overt gangrene, should be assessed in all patients with suspected DVT. ${ }^{2}$

Ultrasonography is the imaging modality of choice for suspected cases of DVT. Although ultrasonography is highly accurate (sensitivity $95 \%$, specificity $96 \%$ ) for the diagnosis of proximal DVT, ${ }^{27}$ it may be difficult to use this type of imaging to assess the iliac veins or inferior vena cava because of excess bowel gas, large body habitus, in situ inferior vena cava filter, postsurgical abdomen or acute abdomen. In patients with severe symptoms and a high clinical suspicion of iliofemoral DVT, contrast-enhanced computed tomography or magnetic resonance venography may be considered. ${ }^{25}$

\section{Management of iliofemoral DVT}

\section{Anticoagulation}

Patients with iliofemoral DVT require anticoagulation similar to that administered to patients with less extensive proximal DVT. Unfractionated heparin by intravenous administration is preferred as the initial anticoagulant for patients who are being considered for thrombus removal strategies, because of its short half-life, which is of benefit where there is potential for both an invasive procedure and exposure to thrombolytic agents. ${ }^{2}$

\section{Patients without cancer}

For patients without cancer, traditional management of acute DVT involves a rapid-acting paren-

\section{Box 1: Classification of recommendations*}

Class I: Benefit $>>$ risk

Procedure or treatment should be performed or administered

Class Ila: Benefit >> risk

Additional studies with focused objectives are needed; it is reasonable to perform the procedure or administer the treatment

Class IIb: Benefit $\geq$ risk

Additional studies with broad objectives are needed, and additional registry data would be helpful; procedure or treatment may be considered

Class III: No benefit OR Class III: Harm

Procedure or treatment should not be performed or administered because it is not helpful and may be harmful

*For details of the classification of recommendations (in relation to levels of evidence), see Appendix 1, available at www.cmaj.ca/lookup/suppl/doi:10.1503/cmaj.141614/-/DC1. 


\section{Box 2: Summary of recommendations for the diagnosis and management of iliofemoral DVT*}

\section{Diagnosis}

1.1 Initial choice of tests is indicated by the clinical pretest likelihood of DVT (Ila, A, weak, high).

1.2All patients with suspected iliofemoral DVT should be screened for phlegmasia cerulea dolens (I, C, strong, low).

1.3 Ultrasonography should be the primary imaging modality for initial diagnosis. This modality may be limited in the assessment of central iliac and caval thrombosis (I, A, strong, high).

1.4Secondary tests (CT or MR venography) are reasonable for cases in which the results of initial diagnostic tests are equivocal or nondiagnostic and there is a high pretest likelihood of DVT (Ila, B, weak, moderate).

\section{Anticoagulation}

2.1 In the acute care setting, all patients should receive anticoagulant therapy for a minimum of 3 months (I, A, strong, high).

2.2 Patients with acute iliofemoral DVT and without cancer should receive initial anticoagulation with parenteral anticoagulants and transition to warfarin (I, A, strong, high).

2.3 For patients with acute iliofemoral DVT and without cancer, treatment with the following alternative regimens may be initiated: low-molecular weight heparin, with switch after 1 week to dabigatran; rivaroxaban; or apixaban (I, B, strong, moderate).

2.4For patients with acute iliofemoral DVT and cancer, low-molecular-weight heparin is suggested (I, B, strong, moderate).

2.5 Patients with acute iliofemoral DVT being considered for or undergoing clot removal may receive initial anticoagulation with a reversible parenteral anticoagulant (intravenous unfractionated heparin) (Ilb, C, weak, low).

\section{Use of IVC filters}

3.1 Insertion of an IVC filter should be considered for patients with acute iliofemoral DVT and a contraindication to systemic anticoagulation (I, C, strong, low).

3.2 Patients with optional recovery (removable) IVC filters should undergo attempted filter removal as soon as the indications for placement are no longer present (I, C, strong, low).

3.3 An optional recovery (removable) IVC filter may remain permanent if the risks of retrieval outweigh the risks of long-term filter use (Ilb, C, weak, low).

\section{Clot removal: surgical intervention}

4.1.a Patients with phlegmasia cerulea dolens should undergo urgent surgical thrombectomy (Ila, C, weak, low).

4.1.b Alternatively, patients with phlegmasia cerulea dolens should undergo endovascular thrombus removal (Illb, C, weak, low).

4.2 Among patients with iliofemoral DVT but without phlegmasia cerulea dolens, open surgical venous thrombectomy may be reasonable for selected patients who are candidates for thrombus removal but have contraindications to thrombolytic therapy (Illb, C, weak, low).

5. Clot removal: systemic thrombolysis

5.1 Systemic thrombolysis is not recommended for patients with iliofemoral DVT (III, B, strong, moderate).

\section{Clot removal: endovenous techniques}

6.1 Clot removal by endovenous techniques may be considered for patients with symptomatic acute iliofemoral DVT to prevent or reduce post-thrombotic syndrome, ideally for patients with onset of symptoms within 21 days, good functional status, reasonable life expectancy and low risk of bleeding (IIb, B, weak, moderate).

6.2 Endovenous techniques may be reasonable as first-line therapy for early thrombus removal (Ilb, C, weak, low).

\section{Use of venous stenting}

7.1 At the time of clot removal, stenting of the iliac venous system, with self-expanding metallic stents, may be considered in cases of clinically significant stenosis or extrinsic compression (Ilb, C, weak, low).

7.2 Stenting of the infrainguinal veins is not recommended (III, C, weak, low).

\section{Management of post-thrombotic syndrome}

8.1 Use of class II (30-40 mm Hg) below-knee elastic compression stockings may begin as soon as possible following initiation of anticoagulant therapy and continue for a minimum of 2 years (IIb, A, weak, high).

8.2 Patients with prior iliofemoral DVT and symptomatic post-thrombotic syndrome may consider the use of class II compression stockings (Illb, B, weak, moderate).

8.3 Patients with prior iliofemoral DVT and symptomatic post-thrombotic syndrome, despite use of elastic compression stockings, may consider the use of intermittent pneumatic compression devices (IIb, B, weak, moderate).

\section{Patient follow-up}

9.1 Patients receiving extended anticoagulant therapy should undergo periodic medical review to reassess the risks and benefits of continuing the therapy (I, C, strong, low).

9.2 Documentation and longitudinal follow-up are recommended for all patients who receive optional recovery IVC filters (I, B, strong, moderate).

Note: $\mathrm{AHA}=$ American Heart Association; $\mathrm{CT}=$ computed tomography; DVT = deep vein thrombosis; GRADE = Grading of Recommendations Assessment, Development and Evaluation; IVC = inferior vena cava; $\mathrm{MR}=$ magnetic resonance.

*In parentheses after each recommendation are shown the class of recommendation and the level of evidence (Roman numeral and letter, respectively, both according to AHA classification; for details, see Box 1 and Appendix 1, available at www.cmaj.ca/lookup/suppl/doi:10.1503/cmaj.141614/-/DC1, and the articles by Jacobs and associates ${ }^{17}$ and Jaff and colleagues ${ }^{18}$ ), followed by the strength of the recommendation and the confidence in the effect estimate (both according to the GRADE classification). The quality of the evidence can be graded as high, moderate, low or very low, according to confidence in the effect estimate, taking into account study design, risk of bias, inconsistency and imprecision of results, and indirectness of evidence (see Brozek and colleagues ${ }^{19}$ for details). A strong recommendation implies that most patients should receive the recommended treatment, whereas a conditional (weak) recommendation implies that different choices will be appropriate for different patients, with the management decision being made in concert with the patient's values and preferences (see Brozek and associates ${ }^{20}$ for details). 
teral agent (unfractionated heparin, low-molecularweight heparin or fondaparinux) with bridging to warfarin (for information on anticoagulant options and dosing, see Appendix 2, available at www. cmaj.ca/lookup/suppl/doi:10.1503/cmaj.141614/-/ DC1). Because warfarin takes four to five days to

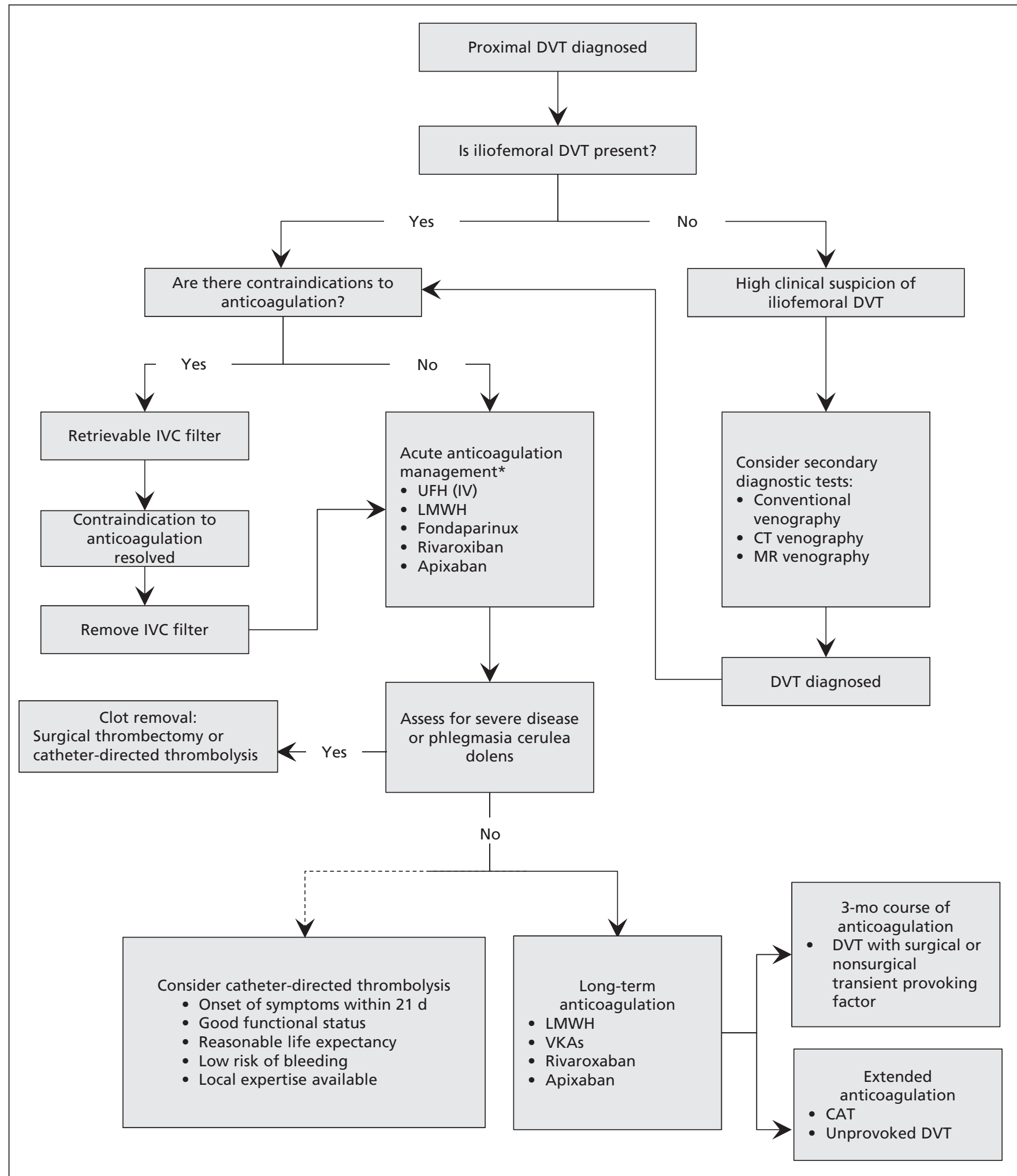

Figure 1: Algorithm for the diagnosis and management of iliofemoral deep vein thrombosis (DVT). In the absence of severe symptoms, catheter-directed thrombolysis may be considered in selected patients with iliofemoral DVT (dotted line). CAT = cancer-associated thromboembolic disease, CT = computed tomography, IV = intravenous, IVC = inferior vena cava, LMWH = low-molecular-weight heparin, $\mathrm{MR}=$ magnetic resonance, $\mathrm{UFH}=$ unfractionated heparin, VKA = vitamin $\mathrm{K}$ antagonist. 
reach peak anticoagulant effect, a minimum fiveday overlap period with a parenteral anticoagulant is required. Relative to unfractionated heparin, low-molecular-weight heparin is associated with lower rates of recurrent symptomatic venous thromboembolism (odds ratio [OR] 0.57, 95\% confidence interval [CI] 0.44-0.75) and major bleeding events (OR 0.50, 95\% CI 0.29-0.85). ${ }^{28}$ Low-molecular-weight heparin and fondaparinux have similar efficacy and safety. ${ }^{29}$ Other advantages of low-molecular-weight heparin and fondaparinux over unfractionated heparin include their ease of administration, the possibility of outpatient treatment and the lower risk of heparininduced thrombocytopenia. ${ }^{30}$

Novel oral anticoagulants (rivaroxaban, dabigatran and apixaban) have also been shown to be effective for the treatment of acute DVT (see Appendix 2). Studies comparing these agents with warfarin for management of acute venous thromboembolism have shown that all three are non-inferior to warfarin for prevention of recurrent venous thromboembolism (dabigatran, hazard ratio [HR] 1.09, 95\% CI 0.76-1.57; rivaroxaban, HR $0.89,95 \%$ CI 0.66-1.19; apixaban, HR $0.84,95 \%$ CI $0.60-1.18) .{ }^{31-35}$ Both rivaroxaban and apixaban were associated with significantly reduced rates of major bleeding relative to conventional therapy (rivaroxaban, HR $0.54,95 \%$ CI 0.37-0.79; apixaban, HR 0.31, 95\% CI 0.17$0.55)$, whereas the major bleeding profile of dabigatran was similar to that of warfarin (HR $0.73,95 \%$ CI $0.48-1.11$ ). Novel oral anticoagulants offer several advantages over warfarin, including no requirement for laboratory monitoring, use of fixed doses, lack of interactions with food and limited interactions with other medications. Drawbacks to their use include the lack of a reversal agent, renal excretion and higher cost. ${ }^{32,34,35}$ Rivaroxaban and apixaban are currently approved in Canada for treatment of acute venous thromboembolism.

Low-molecular-weight heparin and fondaparinux are excreted through renal metabolism and should generally be avoided for patients with severe renal dysfunction (creatinine clearance $<30 \mathrm{~mL} / \mathrm{min}$ ). ${ }^{29}$ Rivaroxaban, dabigatran and apixaban are excreted by both renal and hepatic pathways and therefore should not be used for patients with severe renal failure (creatinine clearance $<30 \mathrm{~mL} / \mathrm{min}$ ) or hepatic dysfunction. ${ }^{36}$

Patients without cancer who have acute DVT require a minimum treatment period of three months, after which anticoagulation may be extended for secondary prophylaxis of venous thromboembolism in those at high risk of recurrent thrombotic events. ${ }^{36}$ Higher-risk patients may include those with unprovoked or recurrent venous thromboembolism or those with high-risk thrombophilias, such as antiphospholipid antibody syndrome or deficiency of antithrombin, protein $\mathrm{C}$ or protein $\mathrm{S}$. Referral to a specialist in venous thromboembolism is appropriate in cases where the benefit or risk of extended anticoagulation is unclear. Traditionally, vitamin $\mathrm{K}$ antagonists have been the agent of choice for these higher-risk patients, although novel oral anticoagulants (rivaroxaban, apixaban, dabigatran) are also suitable options. ${ }^{31,37,38}$

\section{Patients with cancer}

In patients with cancer, low-molecular-weight heparin is the recommended agent for both initial and long-term management of venous thromboembolism. ${ }^{36,39,40}$ Vitamin $\mathrm{K}$ antagonists are less effective than low-molecular-weight heparin for prevention of recurrent venous thromboembolism (HR for low-molecular-weight heparin 0.47, 95\% CI $0.32-0.71) .{ }^{41}$ Additional advantages of lowmolecular-weight heparin for this patient group include lack of interactions with food, no reliance on oral intake or gastrointestinal absorption, no requirement for laboratory monitoring and a shorter half-life, which allows anticoagulation to be interrupted for procedures or thrombocytopenia. If low-molecular-weight heparin is unavailable because of cost or patient preference, vitamin $\mathrm{K}$ antagonists are acceptable alternatives. ${ }^{40}$ Consensus guidelines generally recommend extended anticoagulation, for as long as the active cancer persists. ${ }^{39,40}$ Novel oral anticoagulants have not been formally evaluated in the cancer population, and optimal dosing and drug interactions have not been defined. Therefore, these agents should be avoided in the treatment of cancer-associated DVT.

\section{Inferior vena cava filters}

Despite the widespread use of inferior vena cava filters, robust data on their efficacy and safety are limited to two randomized controlled trials in which anticoagulant therapy was administered concurrently. ${ }^{42-44}$ Adverse events related to the use of these filters are increasingly recognized, although published rates of retrieval are low, ranging from $11 \%$ to $46 \% .{ }^{45-50}$ Given these limitations, expert opinion holds that use of inferior vena cava filters be restricted to patients with iliofemoral DVT who have a contraindication to anticoagulation (such as major bleeding or the need for urgent surgery).

In patients who receive retrievable or optional inferior vena cava filters, anticoagulation should be reinstated and filter retrieval attempted as soon as the contraindication to anticoagulation has resolved. All patients should receive regular 
follow-up and assessment of the risk-benefit ratio of the filter until it has been retrieved or an informed decision has been made for it to remain in situ permanently. Inferior vena cava filters may be made permanent if the risk of retrieval is thought to outweigh the long-term risks of the filter remaining in situ or there is a permanent or long-term contraindication to anticoagulation. ${ }^{51}$

\section{Clot removal and reduction strategies}

The goals of clot removal and reduction strategies are to normalize venous circulation, preserve venous valves, preserve the limb and prevent postthrombotic syndrome. Options include endovascular thrombus removal (catheter-directed thrombolysis), pharmacomechanical thrombolysis, surgical thrombectomy and systemic thrombolysis. However, systemic thrombolysis is associated with inferior efficacy and increased risk of major bleeding compared with the other strategies ${ }^{52}$ and is not recommended for treatment of iliofemoral DVT.

\section{Patients with phlegmasia cerulea dolens}

Given the rarity of phlegmasia cerulea dolens, no high-quality data are available to support the use of clot removal and reduction strategies for patients with this condition. However, systemic anticoagulation cannot rapidly reverse underlying venous obstruction or prevent ongoing tissue damage from ischemia. Therefore, expert opinion and common sense support the use of endovascular thrombus removal or surgical thrombectomy in patients with phlegmasia cerulea dolens, with the goal of reducing the risk of amputation and death. ${ }^{53}$ If local expertise in endovascular thrombus removal or surgical thrombectomy is unavailable, transfer to an institution with experienced personnel is recommended over local systemic thrombolysis.

\section{Patients without phlegmasia cerulea dolens} In patients with iliofemoral DVT without phlegmasia cerulea dolens, early clot removal and recanalization may reduce the risk of postthrombotic syndrome by improving venous patency and preserving venous valvular function. Clot removal strategies should be considered for patients with a short duration of symptoms (less than 21 days), good functional status, reasonable life expectancy and a low risk of bleeding, as the highest-quality studies of clot removal have been performed in this population.

\section{Surgical thrombectomy}

Evidence for surgical thrombectomy for the treatment of iliofemoral DVT is limited to one small randomized trial and a meta-analysis of observational studies that suggested improved vein patency and valve function and fewer symptoms of post-thrombotic syndrome..$^{9-11,54}$ The overall quality of this evidence is low, because of the observational nature of most included studies, the use of surrogate outcomes, small numbers of included patients, high rates of loss to follow-up (ranging from $0 \%$ to 32\%) and heterogeneous definitions of post-thrombotic syndrome.

Drawbacks to the use of surgical thrombectomy include the invasive nature of the intervention, the requirement for general anesthesia and the potential for surgical complications. Surgical thrombectomy has not been directly compared with endovascular thrombus removal, but lowquality evidence suggests that surgical thrombectomy is inferior..$^{54}$ Because endovascular thrombus removal is less invasive and may yield superior results, it is generally favoured for acute clot removal. Surgical thrombectomy may be considered for patients with iliofemoral DVT without phlegmasia cerulea dolens in whom thrombolytic therapy is contraindicated or in settings in which catheter-directed thrombolysis is unavailable. ${ }^{53}$

\section{Endovascular thrombus removal}

Endovascular thrombus removal provides targeted thrombolytic therapy that reduces the complications associated with systemic administration of thrombolytics. Multiple observational studies have shown that endovascular thrombus removal reduces thrombotic burden, with a risk of major bleeding of about $8 \%$ (range $0 \%$ to $24 \%$ ). ${ }^{2.55}$ The CaVenT study, a multicentre, open-label, randomized controlled trial (RCT), has provided the highest-quality evidence. ${ }^{8}$ The study randomly assigned 209 patients to catheter-directed thrombolysis with alteplase plus anticoagulation or anticoagulation alone and showed a $14 \%$ absolute risk reduction in the incidence of post-thrombotic syndrome $(41.1 \%$ v. $55.6 \%, p=0.047$ ) with 20 bleeding events, 4 of which were defined as severe.

In the absence of effective therapies to prevent post-thrombotic syndrome (see "Prevention of post-thrombotic syndrome," below), endovascular thrombus removal remains a promising option, despite the limitations of currently available evidence. Given that all thrombolytic procedures are associated with increased bleeding (albeit less pronounced with endovascular strategies), appropriate patient selection is critical to ensure patient safety and procedural success. Suitable candidates include those with acute iliofemoral DVT, symptom duration less than 21 days, a low risk of bleeding, good functional status and reasonable life expectancy. ${ }^{8}$

\section{Post-thrombotic syndrome}

Iliofemoral DVT is one of the strongest risk factors for post-thrombotic syndrome, the most common complication of DVT. It occurs in $20 \%$ 
to $50 \%$ of affected patients and is associated with decreased quality of life, reduced productivity and higher health care costs. ${ }^{5,56,57}$ However, it is often underappreciated by care providers at the time of presentation because of its late onset, often 12 to 24 months after the initial DVT.

The signs and symptoms of post-thrombotic syndrome, which can range from mild to debilitating, include leg pain and cramping with prolonged standing, dependent edema, pruritus, paresthesias, perimalleolar telangiectasias, varicose veins, erythema, hyperpigmentation, dependent cyanosis and venous ulcers, as defined in the Villalta score of the CaVenT study. ${ }^{8,58}$

\section{Prevention of post-thrombotic syndrome}

Initial RCTs of compression therapy for the prevention of post-thrombotic syndrome in patients with proximal DVT (including iliofemoral DVT) yielded conflicting results, but were hindered by lack of a placebo control, small numbers of patients, single-centre recruitment and open-label design. ${ }^{59-62}$ The recent SOX trial, a multicentre placebo-controlled RCT of external compression stockings for the prevention of post-thrombotic syndrome, randomly assigned patients with a first episode of symptomatic proximal DVT to wear active external compression stockings or placebo stockings (without therapeutic compression) daily for two years. ${ }^{63}$ There was no difference between the groups in cumulative incidence of postthrombotic syndrome (14.2\% with active external compression stockings v. $12.7 \%$ with placebo stockings, $p=0.58$ ), post-thrombotic syndrome severity or recurrent venous thromboembolism. These results bring into question whether the use of external compression stockings should be recommended for all patients with acute symptomatic DVT for the prevention of post-thrombotic syndrome. Drawbacks of external compression therapy include discomfort, difficulty applying stockings and the cost of original and replacement stockings. The only major contraindication to their use is symptomatic peripheral arterial disease. ${ }^{60}$

\section{Treatment of post-thrombotic syndrome}

There is limited evidence for any effective treatment for established post-thrombotic syndrome. Therapeutic strategies include conservative management, such as leg elevation or compression (by external compression stockings or compression devices), pharmacologic therapy (e.g., rutosides, horse chestnut) and endovascular interventions (surgery or venous stenting). ${ }^{57}$ However, given the low risk associated with the use of external compression stockings, it is reasonable for patients with symptomatic post-thrombotic syndrome to undergo a therapeutic trial of such stockings (30$40 \mathrm{~mm} \mathrm{Hg}$ compression at the ankle). Patients can continue to use the stockings so long as they subjectively experience benefit. For patients who are symptomatic despite use of external compression stockings, intermittent pneumatic compression devices may be considered. ${ }^{64}$

\section{Implementation}

This guideline has been endorsed by the Canadian Interventional Radiology Association, with plans for additional dissemination of information through a series of publications in specialtyspecific journals and case reports. The intention is to update the guideline in 2017 , based on planned review of interim evidence.

\section{Other guidelines}

Guidelines have been published recently by the American Heart Association (in 2011) ${ }^{18}$ and the American College of Chest Physicians (in 2012). ${ }^{36}$ The American College of Chest Physicians guideline is substantially broader in scope and detail than the guideline presented here and is more suitable for physicians with expertise in managing venous thromboembolism. The American Heart Association guideline is more similar to this Canadian guideline, but (like the American College of Chest Physicians guideline) it lacks contemporary data on novel oral anticoagulants, elastic compression stockings and endovascular clot removal (such as inclusion of the CaVenT Study ${ }^{8}$ ). Regarding clot removal and reduction strategies in cases where there is clinical equipoise, the American Heart Association guideline provides a stronger recommendation for clot removal or reduction than does the American College of Chest Physicians guideline. Neither of these guidelines takes into account differences in practice and referral within the socialized health care model, factors that may necessitate referral to tertiary centres.

\section{Gaps in knowledge}

Early RCT data have provided evidence of modest effect of clot removal strategies for the prevention of post-thrombotic syndrome. Two large trials comparing catheter-directed techniques with systemic anticoagulation for treatment of acute DVT are currently underway (the ATTRACT study, ClinicalTrials.gov identifier NCT00790335, and the DUTCH-CAVA study, ClinicalTrials.gov identifier NCT00970619) and will help to answer remaining questions about the use of endovascular thrombus removal for iliofemoral DVT. 
The use of inferior vena cava filters for the most common indications has not been subject to appropriately designed trials, and evidence on the long-term efficacy and adverse effects of venous stenting is even more limited. Higherquality data are needed on clinically relevant outcomes and the potential long-term complications of indwelling filters and venous stents.

\section{Conclusion}

Relative to femoropopliteal or distal DVT, iliofemoral DVT carries a higher risk of phlegmasia cerulea dolens, recurrent venous thromboembolism and post-thrombotic syndrome. Anticoagulant therapy remains the cornerstone of management, mainly to prevent recurrent venothromboembolism. However, selected patients with iliofemoral DVT may benefit from alternative clot-management strategies, such as inferior vena cava filters, compression therapy, and clot removal or reduction strategies. Clot removal or reduction strategies are life- and limb-salvaging for patients with phlegmasia cerulea dolens, but they also reduce the risk of postthrombotic syndrome in patients without phlegmasia cerulea dolens, particularly if candidate patients undergo early triage for intervention.

\section{References}

1. White RH. The epidemiology of venous thromboembolism. Circulation 2003;107(23 Suppl 1):I4-8.

2. Vedantham S, Thorpe PE, Cardella JF, et al.; CIRSE and SIR Standards of Practice Committees. Quality improvement guidelines for the treatment of lower extremity deep vein thrombosis with use of endovascular thrombus removal. J Vasc Interv Radiol 2009;20(7 Suppl):S227-39.

3. Kahn SR, Shrier I, Julian JA, et al. Determinants and time course of the postthrombotic syndrome after acute deep venous thrombosis. Ann Intern Med 2008;149:698-707.

4. Douketis JD, Crowther MA, Foster GA, et al. Does the location of thrombosis determine the risk of disease recurrence in patients with proximal deep vein thrombosis? Am J Med 2001;110:515-9.

5. Kahn SR. How I treat postthrombotic syndrome. Blood 2009;114:4624-31.

6. Watson LI, Armon MP. Thrombolysis for acute deep vein thrombosis. Cochrane Database Syst Rev 2004;(4):CD002783.

7. Goldhaber SZ, Buring JE, Lipnick RJ, et al. Pooled analyses of randomized trials of streptokinase and heparin in phlebographically documented acute deep venous thrombosis. Am J Med 1984;76:393-7.

8. Enden T, Haig Y, Kløw NE, et al.; CaVenT Study Group. Longterm outcome after additional catheter-directed thrombolysis versus standard treatment for acute iliofemoral deep vein thrombosis (the CaVenT study): a randomised controlled trial. Lancet 2012;379:31-8.

9. Plate G, Akesson H, Einarsson E, et al. Long-term results of venous thrombectomy combined with a temporary arteriovenous fistula. Eur J Vasc Surg 1990;4:483-9.

10. Plate G, Einarsson E, Ohlin P, et al. Thrombectomy with temporary arteriovenous fistula: the treatment of choice in acute iliofemoral venous thrombosis. J Vasc Surg 1984;1:867-76.

11. Plate G, Eklof B, Norgren L, et al. Venous thrombectomy for iliofemoral vein thrombosis - 10-year results of a prospective randomised study. Eur J Vasc Endovasc Surg 1997;14:367-74.

12. Guyatt GH, Oxman AD, Vist GE, et al. GRADE: an emerging consensus on rating quality of evidence and strength of recommendations. BMJ 2008;336:924-6.

13. Guyatt GH, Oxman AD, Kunz R, et al. What is "quality of evidence" and why is it important to clinicians? BMJ 2008;336:995-8.

14. Guyatt GH, Oxman AD, Kunz R, et al. Incorporating consider- ations of resources use into grading recommendations. BMJ 2008;336:1170-3

15. Guyatt GH, Oxman AD, Kunz R, et al. Going from evidence to recommendations. BMJ 2008;336:1049-51.

16. Jaeschke R, Guyatt GH, Dellinger P, et al. Use of GRADE grid to reach decisions on clinical practice guidelines when consensus is elusive. BMJ 2008;337:a744.

17. Jacobs AK, Kushner FG, Ettinger SM, et al. ACCF/AHA clinical practice guideline methodology summit report: a report of the American College of Cardiology Foundation/American Heart Association Task Force on Practice Guidelines. J Am Coll Cardiol 2013;61:213-65.

18. Jaff MR, McMurtry MS, Archer SL, et al.; Management of massive and submassive pulmonary embolism, iliofemoral deep vein thrombosis, and chronic thromboembolic pulmonary hypertension: a scientific statement from the American Heart Association. Circulation 2011;123:1788-830.

19. Brozek JL, Akl EA, Alonso-Coello P, et al.; GRADE Working Group. Grading quality of evidence and strength of recommendations in clinical practice guidelines. Part 1 of 3 . An overview of the GRADE approach and grading quality of evidence about interventions. Allergy 2009;64:669-77.

20. Brozek JL, Akl EA, Compalati E, et al.; GRADE Working Group. Grading quality of evidence and strength of recommendations in clinical practice guidelines part 3 of 3 . The GRADE approach to developing recommendations. Allergy 2011;66:588-95.

21. Brouwers MC, Kho ME, Browman GP, et al.; AGREE Next Steps Consortium. Development of the AGREE II, part 2: assessment of validity of items and tools to support application. CMAJ 2010;182:E472-8.

22. Brouwers MC, Kho ME, Browman GP, et al.; AGREE Next Steps Consortium. Development of the AGREE II, part 1: performance, usefulness and areas for improvement. CMAJ 2010; 182:1045-52.

23. Fink A, Kosecoff J, Chassin M, et al. Consensus methods: characteristics and guidelines for use. Am J Public Health 1984; 74:979-83.

24. Hirsh J, Lee AY. How we diagnose and treat deep vein thrombosis. Blood 2002;99:3102-10.

25. Bates SM, Jaeschke R, Stevens SM, et al. Diagnosis of DVT: antithrombotic therapy and prevention of thrombosis, 9th ed: American College of Chest Physicians evidence-based clinical practice guidelines. Chest 2012;141(2 Suppl):e351S-418S.

26. Chinsakchai K, Ten Duis K, Moll FL, et al. Trends in management of phlegmasia cerulea dolens. Vasc Endovascular Surg 2011:45:5-14

27. Kearon C, Ginsberg JS, Hirsh J. The role of venous ultrasonography in the diagnosis of suspected deep venous thrombosis and pulmonary embolism. Ann Intern Med 1998;129:1044-9.

28. Erkens PM, Prins MH. Fixed dose subcutaneous low molecular weight heparins versus adjusted dose unfractionated heparin for venous thromboembolism. Cochrane Database Syst Rev 2010;(9):CD001100.

29. Büller HR, Davidson BL, Decousus H, et al. Fondaparinux or enoxaparin for the initial treatment of symptomatic deep venous thrombosis: a randomized trial. Ann Intern Med 2004;140:867-73.

30. Martel N, Lee J, Wells PS. Risk for heparin-induced thrombocytopenia with unfractionated and low-molecular-weight heparin thromboprophylaxis: a meta-analysis. Blood 2005;106:2710-5.

31. Bauersachs R, Berkowitz SD, Brenner B, et al. Oral rivaroxaban for symptomatic venous thromboembolism. N Engl J Med 2010;363:2499-510.

32. Büller HR, Prins MH, Lensin AW, et al. Oral rivaroxaban for the treatment of symptomatic pulmonary embolism. $N$ Engl $J$ Med 2012;366:1287-97.

33. Prins MH, Lensing AW, Bauersachs R, et al.; EINSTEIN Investigators. Oral rivaroxaban versus standard therapy for the treatment of symptomatic venous thromboembolism: a pooled analysis of the EINSTEIN-DVT and PE randomized studies. Thromb J 2013;11:21.

34. Schulman S, Kearon C, Kakkar AK, et al. Dabigatran versus warfarin in the treatment of acute venous thromboembolism. $N$ Engl J Med 2009;361:2342-52.

35. Agnelli G, Buller HR, Cohen A, et al. Oral apixaban for the treatment of acute venous thromboembolism. N Engl J Med 2013;369: 799-808.

36. Kearon C, Akl EA, Comerota AJ, et al. Antithrombotic therapy for VTE disease: antithrombotic therapy and prevention of thrombosis, 9th ed: American College of Chest Physicians evidence-based clinical practice guidelines. Chest 2012;141(2 Suppl):e419S-94S.

37. Agnelli G, Buller HR, Cohen A, et al. Apixaban for extended treatment of venous thromboembolism. N Engl J Med 2013;368: 699-708. 
38. Schulman S, Kearon C, Kakkar AK, et al. Extended use of dabigatran, warfarin, or placebo in venous thromboembolism. $N$ Engl J Med 2013;368:709-18.

39. Cancer-associated venous thromboembolic disease. Version 1.2015. Fort Washington (PA): National Comprehensive Cancer Network; 2015. Available: www.nccn.org/professionals/physician _gls/pdf/vte.pdf (accessed 2015 Sept. 15). Login required to access content.

40. Lyman GH, Khorana AA, Kuderer NM, et al. Venous thromboembolism prophylaxis and treatment in patients with cancer: American Society of Clinical Oncology clinical practice guideline update. J Clin Oncol 2013;31:2189-204.

41. Akl EA, Kahale L, Barba M, et al. Anticoagulation for the longterm treatment of venous thromboembolism in patients with cancer. Cochrane Database Syst Rev 2014;7:CD006650.

42. Decousus H, Leizorovicz A, Parent F, et al. A clinical trial of vena caval filters in the prevention of pulmonary embolism in patients with proximal deep-vein thrombosis. Prévention du Risque d'Embolie Pulmonaire par Interruption Cave Study Group. N Engl J Med 1998;338:409-15.

43. PREPIC Study Group. Eight-year follow-up of patients with permanent vena cava filters in the prevention of pulmonary embolism: the PREPIC (Prevention du Risque d'Embolie Pulmonaire par Interruption Cave) randomized study. Circulation 2005;112:416-22.

44. Mismetti P, Ennezat PV, Quéré I, et al. Prevention of pulmonary embolism recurrences by retrievable vena cava filter: results of the randomized multicenter trial PREPIC 2 [abstract]. J Thromb Haemost 2013;11(Suppl s2):28.

45. Mission JF, Kerlan RK Jr, Tan JH, et al. Rates and predictors of plans for inferior vena cava filter retrieval in hospitalized patients. J Gen Intern Med 2010;25:321-5.

46. McKenzie S, Gibbs H, Leggett D, et al. An Australian experience of retrievable inferior vena cava filters in patients with increased risk of thromboembolic disease. Int Angiol 2010;29:53-7.

47. Seshadri T, Tran H, Lau KK, et al. Ins and outs of inferior vena cava filters in patients with venous thromboembolism: the experience at Monash Medical Centre and review of the published reports. Intern Med J 2008;38:38-43.

48. Tiwari A, Saw C, Li M, et al. Use of inferior vena cava filters in a tertiary referral centre in Australia. ANZ J Surg 2010;80:364-7.

49. Dabbagh O, Nagam N, Chitima-Matsiga R, et al. Retrievable inferior vena cava filters are not getting retrieved: Where is the gap? Thromb Res 2010;126:493-7.

50. Hammond CJ, Bakshi DR, Currie RJ, et al. Audit of the use of IVC filters in the UK: experience from three centres over 12 years. Clin Radiol 2009;64:502-10.

51. Removing retrievable inferior vena cava filters: FDA safety communication. Silver Spring (MD): US Food and Drug Administration; 2014. Available: www.fda.gov/medicaldevices/ safety/alertsandnotices/ucm396377.htm (accessed 2015 Sept. 18).

52. Turpie AG, Levine MN, Hirsh J, et al. Tissue plasminogen activator (rt-PA) vs heparin in deep vein thrombosis. Results of a randomized trial. Chest 1990;97(4 Suppl):172S-175S

53. Meissner MH, Gloviczki P, Comerota AJ, et al. Early thrombus removal strategies for acute deep venous thrombosis: clinical practice guidelines of the Society for Vascular Surgery and the American Venous Forum. J Vasc Surg 2012;55:1449-62.

54. Casey ET, Murad MH, Zumaeta-Garcia M, et al. Treatment of acute iliofemoral deep vein thrombosis. J Vasc Surg 2012, 55:1463-73.

55. Comerota AJ. Thrombolysis for deep venous thrombosis. J Vasc Surg 2012;55:607-11.

56. Kahn SR, Hirsch A, Shrier I. Effect of postthrombotic syndrome on health-related quality of life after deep venous thrombosis. Arch Intern Med 2002;162:1144-8.

57. Baldwin MJ, Moore HM, Rudarakanchana N, et al. Post-thrombotic syndrome: a clinical review. J Thromb Haemost 2013; 11:795-805.

58. Kahn SR, Partsch H, Vedantham S, et al.; Subcommittee on Control of Anticoagulation of the Scientific and Standardization Committee of the International Society on Thrombosis and Haemostasis. Definition of post-thrombotic syndrome of the leg for use in clinical investigations: a recommendation for standardization. J Thromb Haemost 2009;7:879-83.

59. Brandjes DP, Buller HR, Heijboer H, et al. Randomised trial of effect of compression stockings in patients with symptomatic proximal-vein thrombosis. Lancet 1997;349:759-62.
60. Aschwanden M, Jeanneret C, Koller MT, et al. Effect of prolonged treatment with compression stockings to prevent postthrombotic sequelae: a randomized controlled trial. J Vasc Surg 2008;47:1015-21.

61. Ginsberg JS, Hirsh J, Julian J, et al. Prevention and treatment of postphlebitic syndrome: results of a 3-part study. Arch Intern Med 2001;161:2105-9.

62. Prandoni P, Lensing AW, Prins $\mathrm{MH}$, et al. Below-knee elastic compression stockings to prevent the post-thrombotic syndrome: a randomized, controlled trial. Ann Intern Med 2004;141:249-56.

63. Kahn SR, Shapiro S, Wells PS, et al. Compression stockings to prevent post-thrombotic syndrome: a randomised placebocontrolled trial. Lancet 2014;383:880-8.

64. Frisius J, Ebeling M, Karst M, et al. Prevention of venous thromboembolic complications with and without intermittent pneumatic compression in neurosurgical cranial procedures using intraoperative magnetic resonance imaging. A retrospective analysis. Clin Neurol Neurosurg 2015;133:46-54

Competing interests: David Liu has received speaker fees from Cook Medical and Medtronic. Erica Peterson received payment from International Conference Services for her participation in writing this manuscript. Mark Baerlocher has received speaker fees from Boston Scientific and is developing novel antithrombotic/antiplatelet medications for patenting. Leslie Zypchen has served on advisory boards for Pfizer and Celgene. Jason Wong has received consultancy fees from Gore Medical and Pfizer (for activities unrelated to this guideline) and speaker fees from Cook Medical. Otto Moodley has received honoraria from Bayer, Sanofi, Boehringer Ingelheim and Pfizer (for activities outside this guideline). Paul Yenson has served on advisory boards for Alexion and Pfizer and has received an unrestricted educational grant (for work outside this guideline) from Octapharma. James Dooner, Joel Gagnon, Michael Delorme, Chad Kim Sing, Randolph Guzman and Gavin Greenfield have no competing interests to declare.

Affiliations: Department of Radiology (Liu), Division of Hematology, Department of Medicine (Peterson, Zypchen, Yenson), Department of Vascular Surgery (Gagnon), Vancouver General Hospital, Vancouver, BC; Vascular Surgery Victoria (Dooner), Victoria General Hospital, Victoria, BC; Department of Interventional Radiology (Baerlocher), University of Toronto, Toronto, Ont.; Department of Hematology (Delorme), Kelowna General Hospital, Kelowna, BC; Departments of Emergency Medicine (Kim Sing) and Radiology (Wong), Foothills Medical Centre, Calgary, Alta.; Department of Vascular Surgery (Guzman), St. Boniface Hospital, Winnipeg, Man.; Department of Emergency Medicine (Greenfield), University of Calgary, Calgary, Alta.; Department of Hematology (Moodley), Royal University Hospital, Saskatoon, Sask.

Contributors: The guideline and consensus panel design were conceived by Paul Yenson and David Liu. All authors (except Erica Peterson) participated in compiling the data. All authors (except Erica Peterson and Otto Moodley) attended the consensus meeting. All authors participated in subsequent discussions and refinement of the consensus document, as well as in revising the draft manuscript, preparing the article for submission and approving the final manuscript to be published. All authors agree to act as guarantors of the work.

Funding: Funding for the expert panel was provided by the Department of Radiology at the University of British Columbia, Covidien Medical, Cook Medical and Cordis Medical in the form of unrestricted grants to support logistics, transcription of meetings, draft documentation, meeting space and transportation costs.

Endorsing organization: This guideline is endorsed by the Canadian Interventional Radiology Association. 